\title{
Reversible decreased ovarian reserve after conservative ovarian surgery for benign lesion other than endometrioma - case report
}

\author{
Ibrahim A. Abdelazim ${ }^{1,2}$, Gulmira Zhurabekova ${ }^{3}$ \\ ${ }^{1}$ Department of Obstetrics and Gynecology, Ain Shams University, Cairo, Egypt \\ 2Department of Obstetrics and Gynecology, Ahmadi Kuwait Oil (KOC) Company Hospital, Ahmadi, Kuwait \\ ${ }^{3}$ Department of Normal and Topographic Anatomy, West Kazakhstan Marat Ospanov Medical University, Aktobe, Kazakhstan
}

\begin{abstract}
A 36-year-old woman presented with abdominal pain and diagnosed provisionally as complicated ovarian cyst. The trans-vaginal ultrasound (TVS) done for the studied woman showed, well-defined solid mass, measuring $10 \times 8 \mathrm{~cm}$ related to the anterior uterine wall most probably subserous uterine leiomyoma or ovarian fibro$\mathrm{ma}$. The TVS finding of left solid mass was confirmed by the magnetic resonance imaging (MRI). At laparotomy, the solid mass was originating from the left ovary and the right ovary and uterus were completely normal. The left ovarian mass excised (confirmed as ovarian fibroma by histological examination), and more than half of the left ovary was preserved during surgery. The pre-operative ovarian reserve hormones, anti-Müllerian hormone $(\mathrm{AMH})$, follicle stimulating hormone (FSH), and luteinizing hormone (LH) were completely normal. Post-operative follow-up of the studied woman showed regular menstrual rhythm and duration, elevated FSH and LH for one year after surgery and both the FSH and LH returned to normal levels at the end of the first post-operative year.

This report represents the finding of reversible decrease ovarian reserve (RDOR) after conservative ovarian surgery for benign lesion other than endometrioma to minimise normal ovarian tissue damage during surgery as much as possible and to counsel women at risk of DOR that any ovarian surgery may be associated with further decrease in the ovarian reserve and reproductive ability.
\end{abstract}

Key words: reversible, decreased, ovarian, reserve, RDOR, conservative, surgery, endometrioma.

\section{Introduction}

The optimum age for the female reproductive ability is 18-30 years, after which there is gradual decline in the reproductive ability and ovarian function [1]. Ovarian surgery has negative impact on the ovarian reserve and reproductive ability [1].

Somigliana et al. studied the ovarian response to controlled ovarian hyperstimulation $(\mathrm{COH})$ during in-vitro fertilization (IVF) in women who had an excision of endometrioma in the past [2]. Somigliana et al. found significant difference in the number of oocytes retrieved in the operated ovary compared to the non-operated ovary irrespective the size of endometriomas [2]. Yılmaz et al. found that the surgical excision of endometrioma associated with decreased ovarian reserve (DOR) [3].

The effect of surgical excision of endometrioma on the ovarian reserve is extensively studied and it is difficult to conclude whether the DOR after surgical excision of endometrioma is because of surgery alone and/or due to microscopic implants of endometriosis within the ovarian stroma around the excised endometrioma [1].
In addition, the studies regarding the effect of surgical removal of benign ovarian lesions other than endometriomas on the ovarian reserve are limited. Therefore, this report represents finding of reversible decreased ovarian reserve (RDOR) after conservative ovarian surgery for benign lesion other than endometrioma.

\section{Case report}

A 36-year-old woman presented with abdominal pain and diagnosed provisionally as complicated ovarian cyst. The trans-vaginal ultrasound (TVS) done for the studied woman showed, well-defined solid mass, measuring $10 \times 8 \mathrm{~cm}$ related to the anterior uterine wall most probably subserous uterine leiomyoma or ovarian fibroma. The TVS finding of left solid mass was confirmed by the magnetic resonance imaging (MRI).

The studied woman signed written consent, agreed for exploratory laparotomy after departmental approval. At laparotomy, the solid mass was originating from the left ovary and the right ovary and uterus were 


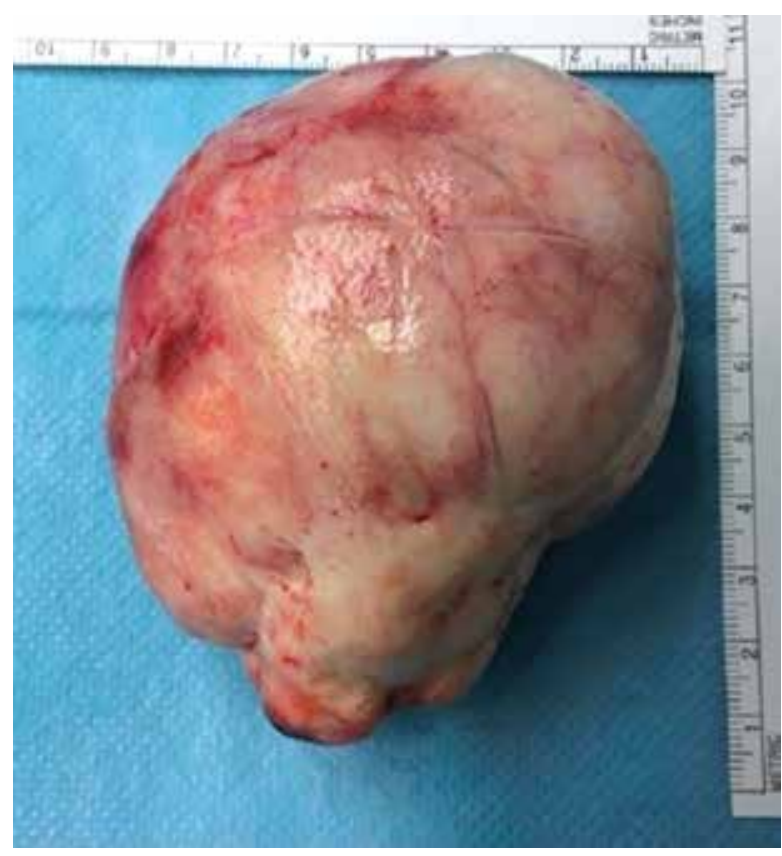

Fig. 1. Excised left ovarian fibroma $10 \times 8 \mathrm{~cm}$

completely normal. The left ovarian mass excised [4] (Fig. 1), and more than half of the left ovary was preserved during surgery for future fertility.

The pre-operative ovarian reserve hormones, anti-Müllerian hormone (AMH $2.3 \mathrm{ng} / \mathrm{ml})$, follicle stimulating hormone (FSH $3.5 \mathrm{mlU} / \mathrm{ml}$ ), and luteinizing hormone (LH $3.0 \mathrm{mIU} / \mathrm{ml}$ ) were completely normal. The microscopic examination of the excised mass showed bundles of spindle cells without mitotic activity, confirming the diagnosis of ovarian fibroma.

Post-operative follow-up of the studied woman for one year showed; regular menstrual rhythm, duration, elevated FSH (Fig. 2) and LH (Fig. 3) and both the FSH and $\mathrm{LH}$ returned to normal levels at the end of the first post-operative year. Patient's body weight, body mass index (BMI), $\mathrm{AMH}$, prolactin and thyroid profile (Fig. 4) did not show any changes during the post-operative follow-up.

This report represents finding of RDOR after conservative ovarian surgery for benign lesion other than endometrioma to minimise normal ovarian tissue damage during surgery as much as possible and to counsel women at risk of DOR that any ovarian surgery may be associated with further decrease in the ovarian reserve and reproductive ability.

Finding of RDOR after conservative ovarian surgery for benign lesion other than endometrioma included: 1) elevated both FSH and $\mathrm{LH}$ (both the FSH and $\mathrm{LH}$ returned to normal levels within 1-2 years post-operative); 2) regular menstrual rhythm and duration; 3) no change in the body weight and/or BMI; 4) normal $\mathrm{AMH}$, prolactin and thyroid profile.

\begin{tabular}{c|c|c|c|c}
\hline Date & Time & Result & Units & Reference \\
\hline $18 / 12 / 19$ & $14: 41$ & $3.32 \varnothing$ & $\mathrm{mIU} / \mathrm{mL}$ & $1.7-13.7$ \\
\hline $19 / 11 / 19$ & $14: 35$ & $27.77 \mathrm{H} Q \mathrm{mIU} / \mathrm{mL}$ & $1.7-13.7$ \\
\hline $10 / 7 / 19$ & $13: 10$ & $15.01 \mathrm{H} Q$ & $\mathrm{mIU} / \mathrm{mL}$ & $1.1-13.3$ \\
\hline $27 / 2 / 19$ & $13: 49$ & $14.50 \mathrm{H} Q \mathrm{mIU} / \mathrm{mL}$ & $1.7-13.7$ \\
\hline $30 / 1 / 19$ & $17: 43$ & $27.38 \mathrm{H} Q \mathrm{mIU} / \mathrm{mL}$ & $1.7-13.7$ \\
\hline $31 / 12 / 18$ & $14: 11$ & $24.58 \mathrm{H} Q \mathrm{mIU} / \mathrm{mL}$ & $1.7-13.7$
\end{tabular}

Fig. 2. Follicle stimulating hormone (FSH) levels during the first post-operative year of follow-up

\begin{tabular}{c|c|c|c|c} 
Date & Time & Result & Units & Reference \\
\hline $18 / 12 / 19$ & $14: 41$ & $2.70 Q$ & $\mathrm{mIU} / \mathrm{mL}$ & $1.4-9.4$ \\
\hline $19 / 11 / 19$ & $14: 35$ & $11.00 \mathrm{H} Q$ & $\mathrm{mIU} / \mathrm{mL}$ & $1.4-9.4$ \\
\hline $10 / 7 / 19$ & $13: 10$ & $8.41 \varnothing$ & $\mathrm{mIU} / \mathrm{mL}$ & $1.4-9.4$ \\
\hline $27 / 2 / 19$ & $13: 49$ & $5.80 \varnothing$ & $\mathrm{mIU} / \mathrm{mL}$ & $1.4-9.4$ \\
\hline $30 / 1 / 19$ & $17: 43$ & $11.51 \mathrm{H} Q$ & $\mathrm{mIU} / \mathrm{mL}$ & $1.4-9.4$ \\
\hline $31 / 12 / 18$ & $14: 11$ & $9.86 \mathrm{H} Q$ & $\mathrm{mIU} / \mathrm{mL}$ & $1.4-9.4$
\end{tabular}

Fig. 3. Luteinizing hormone (LH) levels during the first post-operative year of follow-up

\begin{tabular}{l}
\multicolumn{2}{c}{$\begin{array}{l}\text { Specimen Collected } \\
18 \text { Dec 2019 14:41 }\end{array}$} \\
\begin{tabular}{|l|l|}
\hline Prolactin & $248.6 \mathrm{uIU} / \mathrm{mL}(102-496)$ \\
\hline Free Triodothyronine & $4.16 \mathrm{pmo} / \mathrm{L}(2.81-7.11)$ \\
\hline Free Thyroxine & $12.42 \mathrm{pmol} /(12.0-22.0)$ \\
\hline Thyroid Stimulating Hormone (TSH) & $0.918 \mathrm{uIU} / \mathrm{mL}(0.27-4.20)$ \\
\hline Luteinizing Hormone & $2.70 \mathrm{mlU} / \mathrm{mL}(1.4-9.4)$ \\
\hline Follicle Stimulating Hormone & $3.32 \mathrm{mIU} / \mathrm{mL}(1.7-13.7)$ \\
\hline
\end{tabular}
\end{tabular}

Fig. 4. Follicle stimulating hormone (FSH), luteinizing hormone $(\mathrm{LH})$, prolactin and thyroid profiles at the end of the first post-operative year of follow-up

\section{Discussion}

Ovarian reserve reflects the number of the oocytes available in the ovaries of any woman and her reproductive ability [5]. Women at increased risk of DOR include: 1) > 35 years old; 2) family history of premature ovarian failure; 3 ) past history of ovarian surgery and/ 
or radiation; 4) unexplained infertility [6, 7]. In addition; Balmagambetova et al. concluded that exposure to environmental hazards may destroy a considerable number of the ovarian follicles with subsequent DOR [8].

National Institute for Health and Care Excellence (NICE) guidelines concluded that sufficient ovarian reserve diagnosed by either antral follicle count (AFC) $>4$ or serum $\mathrm{AMH}$ level $>5.4 \mathrm{pmol} / \mathrm{l}$ or serum FSH level $<8.9 \mathrm{IU} / \mathrm{I}[9]$.

The studied woman was at risk of DOR because of her age (over 35 years) $[6,7]$ and because of ovarian surgery. She was worried about her fertility and reproductive ability; therefore, the hormonal profile done for her every month during the first 3 post-operative months, then every 3-4 months during the first postoperative year.

Post-operative follow-up of the studied woman for one-year showed; regular menstrual rhythm, duration, elevated FSH and LH for one year after surgery (both the FSH and $\mathrm{LH}$ returned to normal levels at the end of the first post-operative year). Patient's body weight, $\mathrm{BMI}, \mathrm{AMH}$, prolactin and thyroid profile did not show any changes during the post-operative follow-up.

The finding of RDOR after conservative ovarian surgery lesion other than endometrioma included: 1) elevated both $\mathrm{FSH}$ and $\mathrm{LH}$ (both the FSH and $\mathrm{LH}$ returned to normal levels within 1-2 years post-operative; 2) regular menstrual rhythm and duration; 3 ) no change in the body weight and/or BMI; 4) Normal AMH, prolactin and thyroid profile. The studied woman was at risk of DOR and she developed RDOR for one year after surgery according to the NICE guidelines which diagnosed sufficient ovarian reserve by serum FSH level $<8.9$ IU/I [9].

Although, Yılmaz et al. concluded that the bipolar diathermy used during surgical excision of endometrioma is the most harmful hemostatic modality to ovarian reserve [3] and Deckers et al. systematic review concluded that the bipolar electrocoagulation negatively impacts ovarian reserve, especially for women with reproductive goals [10].

Owczarek et al. studied the effect of the hemostasis techniques on ovarian reserve following laparoscopic enucleation of endometriotic cysts and concluded that the laparoscopic enucleation of endometriotic cysts leads to DOR, regardless the hemostasis technique used [11].

Recently, Younis et al. systematic review concluded that endometrioma cystectomy (especially bilateral), associated with DOR and may have no obvious reproductive advantage, therefore, conservative treatment should be considered as the first line of treatment [12]. Indeed, it's not clear whether the DOR after endometrioma excision is because of surgery alone and/or due to microscopic implants of endometriosis within the ovarian stroma around the excised endometrioma [1].
During the surgical excision of the left ovarian fibroma of the studied woman, the surgeons did not use any electrocoagulation hemostatic modality (only surgical stitches used), half of the left ovary was preserved, and the right ovary was completely normal. Despite of the above-mentioned conservative measures, the studied woman developed RDOR for the first post-operative year.

The effect of surgical excision of endometrioma on the ovarian reserve is extensively studied, while, the studies regarding the effect of surgical removal of benign ovarian lesions other than endometriomas on the ovarian reserve are limited.

To the best of our knowledge, this report is the first report represents the finding of RDOR after conservative surgery for benign lesion other than endometrioma and large studies are needed to confirm the authors' finding.

\section{Conclusions}

This report represents the finding of RDOR after conservative ovarian surgery for benign lesion other than endometrioma to minimise normal ovarian tissue damage during surgery as much as possible and to counsel women at risk of DOR that any ovarian surgery may be associated with further decrease in the ovarian reserve and reproductive ability.

\section{Acknowledgments}

Authors are grateful for the studied woman, who agreed to publish her case as a case report.

\section{Disclosure}

The authors report no conflict of interest.

\section{References}

1. Kalra GS, Campbell S, Nargund G. Ovarian reserve may be compromised after adnexal surgery: Are we sufficiently fertility-focused in our surgical training? Facts Views Vis Obgyn 2016; 8: 104-108.

2. Somigliana E, Ragni G, Benedetti F, et al. Does laparoscopic excision of endometriotic ovarian cysts significantly affect ovarian reserve? Insights from IVF cycles. Hum Reprod 2003; 18: 2450-2453.

3. Yılmaz Hanege B, Güler Çekıç S, Ata B. Endometrioma and ovarian reserve: effects of endometriomata per se and its surgical treatment on the ovarian reserve. Facts Views Vis Obgyn 2019; 11: 151-157.

4. Abdelazim IA, Abu-Faza M, Abdelrazek K, et al. Ovarian fibroma commonly misdiagnosed as uterine leiomyoma. Gynecol Minim Invasive Ther 2019; 9: 36-38.

5. Practice Committee of the American Society for Reproductive Medicine. Testing and interpreting measures of ovarian reserve: a committee opinion. Fertil Steril 2015; 103: e9-e17.

6. Abdelazim IA, Abu-Faza M, Shikanova S, et al. Methods of evaluation of the ovarian reserve. J Obstet Gynecol Investig 2018; 1: 62-66.

7. Prashant P, Savvas M, Abdelazim I, Zhurabekova G. Primary ovarian insufficiency and fertility preservation: review article. J Obstet Gynecol Investig 2018; 1: 79-83. 
8. Balmagambetova A, Abdelazim IA, Bekmukhambetov E, et al. Ovarian parameters and ovarian blood flow of women living in the area of environmental crisis. Eur J Obstet Gynecol Reprod Biol 2016; 200: 68-71.

9. Fertility problems: assessment and treatment. Clinical guideline [CG156]. (February 2013). https://www.nice.org.uk/guidance/cg156/ chapter/recommendations (access: March 2020).

10. Deckers P, Ribeiro SC, Simões RDS, et al. Systematic review and metaanalysis of the effect of bipolar electrocoagulation during laparoscopic ovarian endometrioma stripping on ovarian reserve. Int J Gynaecol Obstet 2018; 140: 11-17

11. Owczarek D, Malinowski A, Wilczyński M. Ovarian reserve evaluation after laparoscopic cyst enucleation, depending on applied haemostasis technique and with particular consideration of endometrial cysts. Prz Menopauzalny 2018; 17: 22-27.

12. Younis JS, Shapso N, Fleming R, et al. Impact of unilateral versus bilateral ovarian endometriotic cystectomy on ovarian reserve: a systematic review and meta-analysis. Hum Reprod Update 2019; 25: 375-391. 